\title{
Benign Paroxysmal Positional Vertigo (BPPV): History, Pathophysiology, Office Treatment and Future Directions
}

\author{
Jeremy Hornibrook \\ Department of Otolaryngology, Head and Neck Surgery, Christchurch Hospital, 2 Riccarton Avenue, Christchurch 8011, New Zealand \\ Correspondence should be addressed to Jeremy Hornibrook, jeremy@jhornibrook.com
}

Received 12 March 2011; Accepted 18 May 2011

Academic Editor: Bill Gibson

Copyright () 2011 Jeremy Hornibrook. This is an open access article distributed under the Creative Commons Attribution License, which permits unrestricted use, distribution, and reproduction in any medium, provided the original work is properly cited.

BPPV is the most common cause of vertigo. It most often occurs spontaneously in the 50 to 70 year age group. In younger individuals it is the commonest cause of vertigo following head injury. There is a wide spectrum of severity from inconsistent positional vertigo to continuous vertigo provoked by any head movement. It is likely to be a cause of falls and other morbidity in the elderly. Misdiagnosis can result in unnecessary tests. The cardinal features and a diagnostic test were clarified in 1952 by Dix and Hallpike. Subsequently, it has been established that the symptoms are attributable to detached otoconia in any of the semicircular canals. BPPV symptoms can resolve spontaneously but can last for days, weeks, months, and years. Unusual patterns of nystagmus and nonrepsonse to treatment may suggest central pathology. Diagnostic strategies and the simplest "office" treatment techniques are described. Future directions for research are discussed.

\section{History and Pathophysiology}

Benign paroxysmal positional vertigo (BPPV) is the most common vertiginous disorder in the community. The cardinal symptom is sudden vertigo induced by a change in head position: turning over in bed, lying down in bed (or at the dentist or hairdresser), looking up, stooping, or any sudden change in head position. There is a wide spectrum of severity. Mild symptoms are inconsistent positional vertigo. Moderate symptoms are frequent positional attacks with disequilibrium between. When severe, vertigo is provoked by most head movements, giving an impression of continuous vertigo. The symptoms can last for days, weeks, months, or years, or be recurrent over many years.

The earliest reference to it may have been by Shakespeare in "Romeo and Juliet" [1] In Act I, Scene II [enter Romeo and Bevolio] Bevolio says "Tut man, one fire burns out another's burning. One pain is lessen'd by another's anguish; turn giddy, and be holp by backwards turning...." In the medical literature the first descriptions of positionally induced vertigo are attributed to Adler [2] and later Barany [3], who believed it was a disorder of the otolith organs. Barany elicited vertigo in a 27 -year-old woman by turning her head from side to side in a supine position and noted “...there appeared a strong rotatory nystagmus to the right with a vertical component upwards, which when looking to the right was purely rotatory, and when looking to the left was purely vertical.” In 1952 Margaret Dix (1911-1981) and Charles Hallpike (1900-1979) [4] at Queen Square Hospital, based on 100 patients, presented a symptomatological definition and a provocative positional test for what they called "positional nystagmus of the benign positional type." For symptoms they note: "The story given by the patient is characteristically that the giddiness comes on when he lies down in bed or when he turns over in bed, or when such a position is taken up during the day; for instance lying down beneath a car or in throwing the head backward to paint a ceiling." Their diagnostic test: "....the patient is first seated upon the couch with the head turned to one side and the gaze fixed firmly on the examiner's forehead. The examiner then grasps the patient's forehead firmly between his hands and briskly pushes the patient back into the critical position [30 degrees below the level of the couch and turned some 30 to 45 degrees to one side]. The reaction which results calls for some detailed description." As did Barany they noted a torsional nystagmus with the upper pole of the eye beating (fast phase) toward the ground and that it "fatigued" on retesting. Additionally, they observed a 
response latency of approximately 5 seconds, a crescendo and decline of nystagmus, and a reversal of the nystagmus as the patient sits up. To eliminate the possibility that the response could be induced by vascular occlusion from rotation of the neck they tested patients on an apparatus which avoided it. The same response occurred. In Britain Hallpike was a pioneer of temporal bone histology. The right temporal bone of 40-year-old woman with "positional nystagmus of the benign positional type...to the right with the right ear undermost" was examined. In the macula of the utricle, the otolithic membrane was absent. They concluded: "The general picture is one of chronic tissue changes resulting either from infection or trauma..." and "We are thus directed to the conclusion that the lesion is a peripheral one and in the labyrinth towards which, when undermost, the nystagmus is directed". Hallpike provided further evidence for a peripheral cause by abolishing symptoms in two patients with a chemical labyrinthectomy of an acoustically dead ear [5] and in one patient by an eight nerve section [6]. Both Barany and Dix and Hallpike concluded that "positional nystagmus of the benign positional type" was caused by disorder of the utricular macula.

By the early 19th century the bony and some membranous structure of the inner ear were anatomically well described but their functions unproven. Common notions were the following. The cochlea was responsible for mediating the nature and pitch of sound; the saccule and utricle were for perception of loudness, and the semicircular canals for transmission of bone-conducted sound and perception of sound direction [7]. Marie-Jean Flourens (1794-1867) was a professor of comparative anatomy in Paris, and in 1824 he published his experimental results on pigeon semicircular canals [8]: "If the membranous ducts are injured, a painful sensitivity to tones is observed, accompanied by abrupt and violent movements of the head.... If the horizontal canals are severed, the animal turns on its vertical axis; if the posterior vertical canal is severed the animal rolls over backward, and if the anterior vertical canal is severed the animal falls forward...." Flourens concluded that the semicircular canals inhibited motion ("forces moderatrices") and influenced direction of motion, rather than having a role in balance. Flourens' work had been largely ignored but was known to Prosper Meniere and acknowledged in his final paper in 1861 [9]. According to Adam Politzer (1835-1920) in his "History of Otology" [10] "the realization that the vestibular and semicircular canal structures are not organs of sound perception, that sound perception is transmitted solely through the cochlea, is the single most important result of Flourens' experiments". However it was another sixty years until a more sophisticated understanding of semicircular canal functions and their generated nystagmus was achieved by Julius Ewald (1855-1921) who was later Professor of Physiology at the University of Strassburg (now Strasbourg). In pigeons, he cannulated each semicircular canal and applied negative and positive pressures and observed the directions and intensity of the induced nystagmus [11]. The two major findings have become known as Ewalds' Laws: (1) the direction of the induced nystagmus is in the plane of the canal being stimulated, and (2) in the horizontal canal an ampullopetal (towards the vestibule) movement of endolymph causes the greatest response where as in the posterior and superior canals an ampullofugal (away from the vestibule) endolymph movement causes the greatest response. At the time the differences were perplexing, as expressed by a writer in 1920 [12]: "It is, however, difficult to imagine how the same endolymph current can be stimulating for the one endorgan and hindering for the other".

Thirty years later the advent of the electron microscope allowed a more detailed view of inner ear ultrastructure. In 1954 Wersall [13] showed that each vestibular sensory cell has one kinocilium and many stereocilia. The finding of morphological polarization of kinocilia on vestibular sensor cells $[14,15]$ explained Ewald's paradox. In horizontal canal cristae the kinocilium is on the vestibule side of the stereocilia; in the posterior and superior canals the kinocilium is on the canal side of the stereocilia (Figure 1). In the 1960s, experiments in cats [16] clarified the relationship between canal receptors and extraocular muscles. Each receptor is connected to one ipsilateral and one contralateral muscle. The second order neurones are either excitatory (to the agonist muscles) or inhibitory (to the antagonist muscles) (Figures 2, 3, 4, and 5).

In 1962 Harold Schuknecht (1917-1996) at Harvard University in Boston [17] proposed that BPPV "might be caused by detached utricular otoconia, acting upon the cupula of the posterior semicircular canal. Although at that time there were no confirming human pathological studies, the concept seemed plausible from a purely theoretical point of view." In 1969 Schuknecht [18, 19] confirmed finding basophilic staining masses attached to the posterior canal cupula in patients who had had BPPV symptoms. He called this cupulolithiasis (heavy cupula) and assumed the masses were detached utricular otoliths which were removed by decalcification in preparation. This was supported by Gacek's report of five patients where the selective resection of the posterior ampullary nerve abolished BPPV symptoms [20]. Cupulothiasis became the dominant theory for nearly thirty years, although it did not explain the variable and often long latency and fatiguability of the nystagmus. It was the impetus for two early specific treatments. Previously "treatment" had been by Cawthorne's exercises in which the patient was instructed to repeat continually any movement which caused the vertigo until it ceased, on the assumption that central adaption was occurring [21]. Based on the cupulolithiasis theory Brandt and Daroff [22] devised an inpatient treatment where subjects lay down to the provocative side, sat up for thirty seconds, and then lay to the other side every three hours. After seven to ten days, 61 of 67 subjects were free of symptoms. The assumed aim was detachment of the particle from the posterior canal cupula. In France Semont (a physiotherapist) and Sterkers [23, 24] modified this to a logical physician-controlled treatment they called the Liberatory maneuver, now known as the Semont maneuver (Figure 6). The patient is lain down to the side of the symptomatic ear, facing down. When the nystagmus ceases, the patient is moved rapidly through 90 degrees to the opposite side (where the symptomatic ear becomes uppermost). Either immediately or up to 15 seconds later 


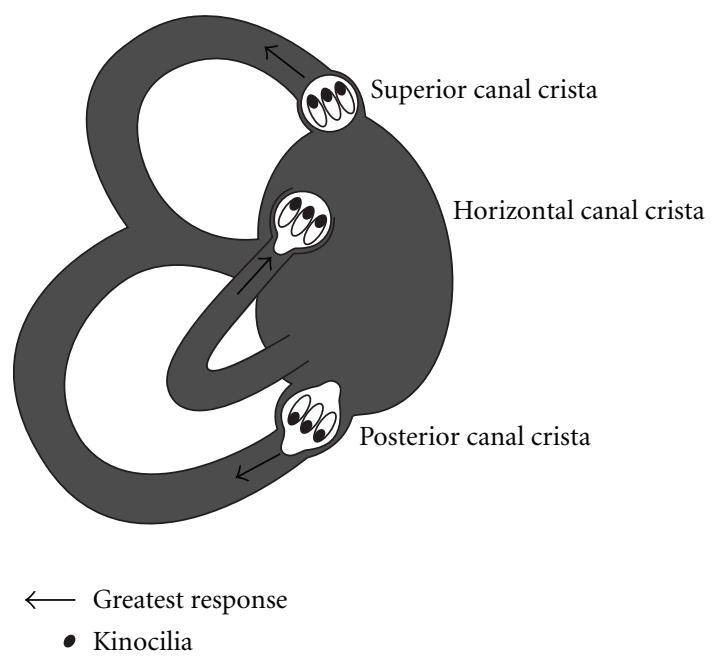

FIGURE 1: Orientation of kinocilia in the semicircular canal cristae. In the horizontal canal kinocilia are on the vestibule side. In the posterior and superior canals kinocilia are on the canal side.
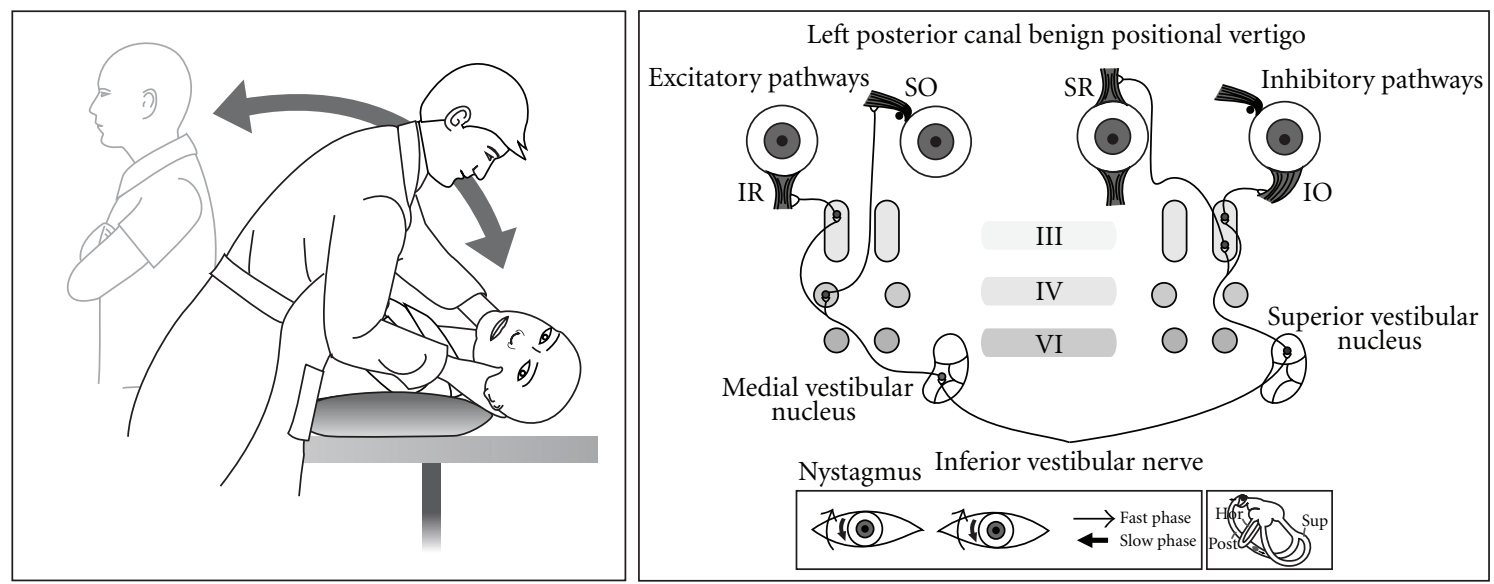

Figure 2: Posterior canal BPPV in a left ear showing Dix Hallpike test, inner ear, and receptor connections to the extraocular muscles.

the patient experiences vertigo and has nystagmus identical to the symptomatic side. The technique was little known outside France.

In attempting to explain the latency and fatiguability of BPPV nystagmus, Hall et al. [25] (at the University of London, Ontario) and later Epley [26] (a solo private practice otologist in Portland, Oregon) made models of the semicircular canals and proposed that they were better explained by free-floating particles in the posterior canal, which Epley called canalithiasis. Also at the University of London, Ontario, Parnes and McClure, in attempting a surgical posterior canal occlusion, observed and photographed free otoconia in the endolymphatic compartment [27]. Based on his models Epley proposed a controlled set of head movements he called the canalith repositioning procedure (CRP) [28] (Figure 7). Epley had presented this as an instruction course at the American Academy of Otolaryngology, Head and Neck Surgery meetings since 1980 and endured considerable derision because he used a heavy massage vibrator over the mastoid process [29].
After seeing canaliths at operation, Parnes [30] described an almost identical particle repositioning maneuver (PRM) (often known as the Modified Epley maneuver) whose main difference is its slower pace.

BPPV ( $85 \%$ posterior canal) is now recognized as the most common cause of vertigo in adults. It is estimated that $2.4 \%$ of people experience at least episode in their life [31]. $9 \%$ of residents in a home for the elderly were found to have BBPV [32]. The onset is most commonly between the fifth and seventh decades. It is the most common cause of vertigo after a head injury $[33,34]$. An episode of vestibular neuritis [35] and a period of bed rest [36] are common antecedents. Omission of a simple clinical test can result in patients undergoing unnecessary, expensive investigations [37].

Previously "nontypical" forms of positionally induced nystagmus were assumed to always have a central cause. While performing CRPS, Epley observed a sudden change of "typical" torsional posterior canal nystagmus to horizontal direction-changing nystagmus and deduced the nystagmus 

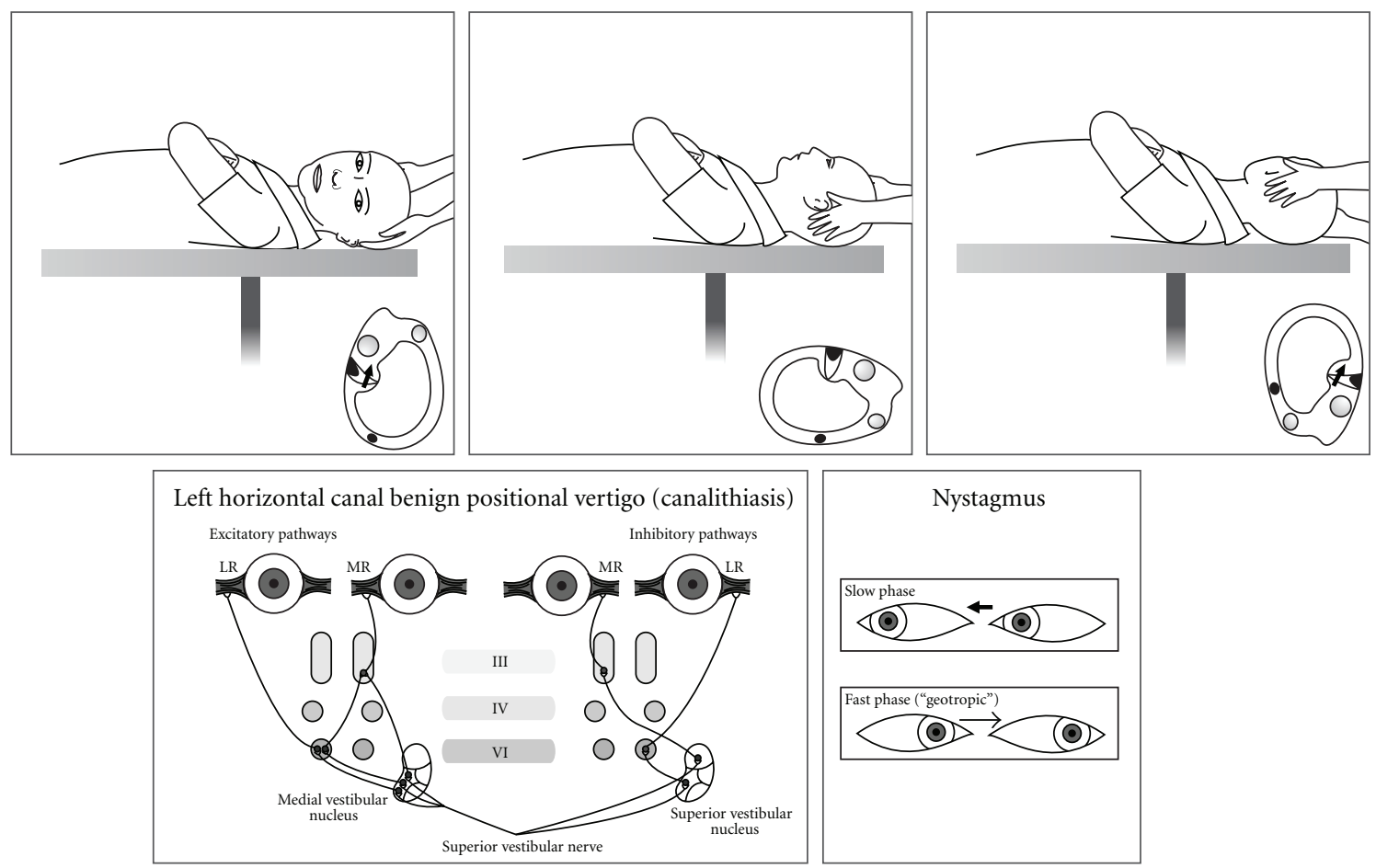

FIgURE 3: Horizontal canal BPPV (canalithiasis) in a left ear showing Head Roll test, inner ear, and receptor connections to the extraocular muscles.
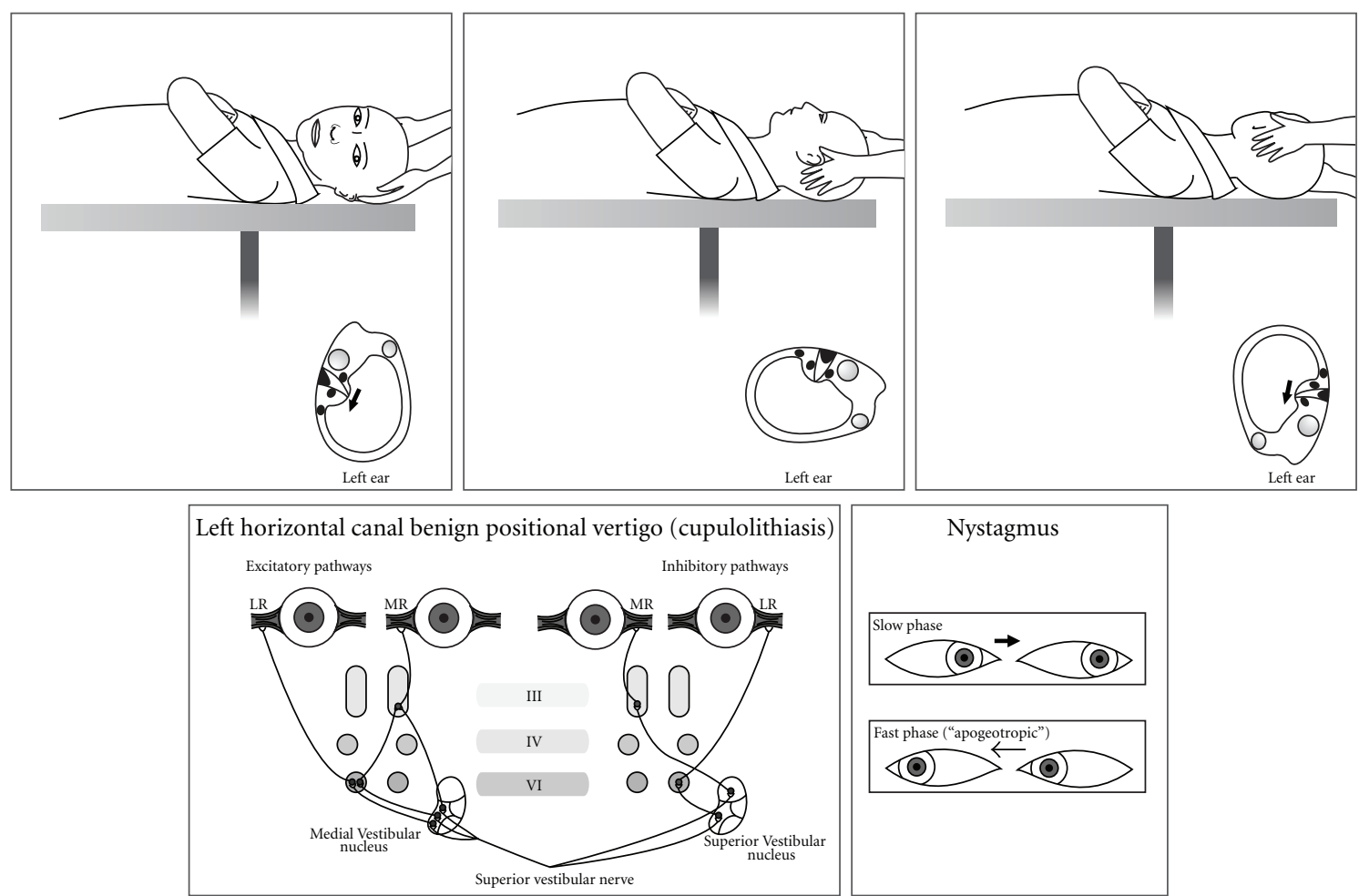

FIGURE 4: Horizontal canal BPPV (cupulolithiasis) in a left ear showing Head Roll test, inner ear, and receptor connections to the extraocular muscles. 

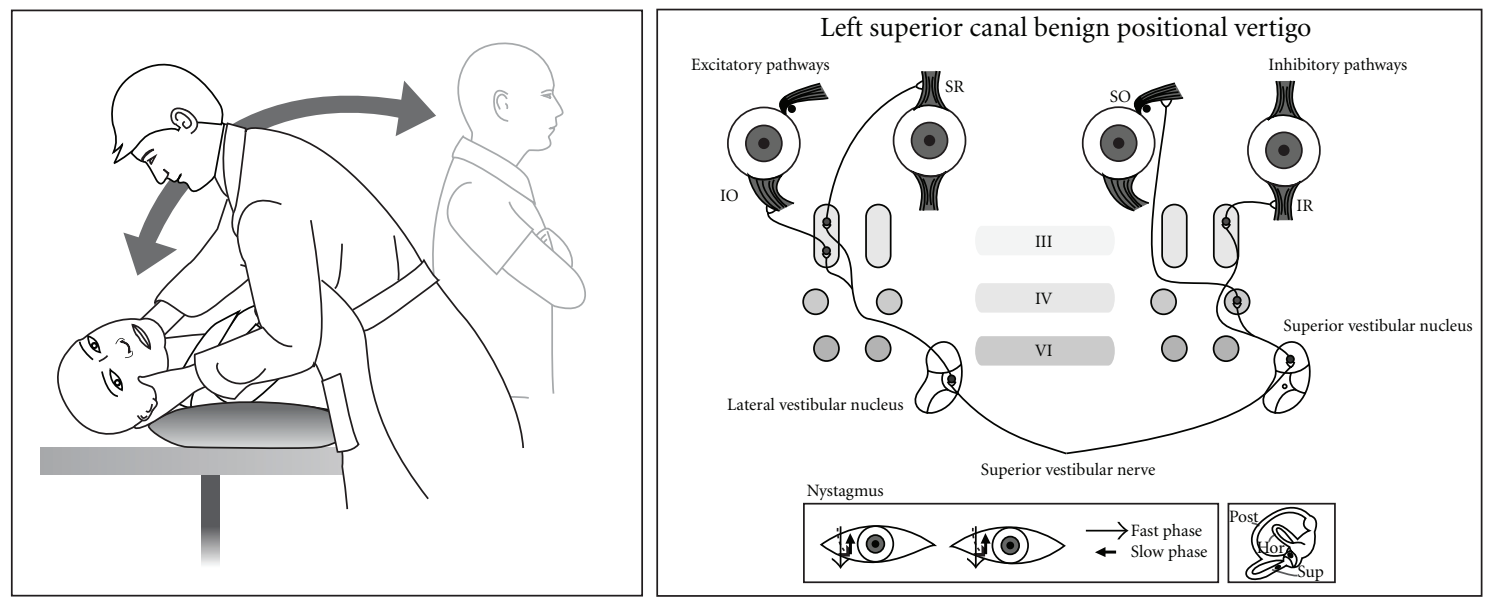

FIGURE 5: Superior canal BPV in a left ear showing Dix Hallpike test, inner ear, and receptor connections to the extraocular muscles.

that would be caused by otoconia in the horizontal and even the superior canal [38]. Without clinical proof Epley predicted the logical treatment for horizontal canal BPPV would be a 360 degree horizontal plane rotation away from the symptomatic ear. In 1985 McClure [39] had published the electronystagmographic (ENG) traces of seven subjects who had intense positional vertigo and direction-changing horizontal nystagmus when supine. The fast phase was towards the undermost ear (geotropic). McClure suspected a "viscous plug" in the horizontal canal which was causing a piston effect on the horizontal canal receptor. As discovered by Ewald, an ampullopetal (towards the vestibule) cupula deflection is known to cause the most intense nystagmus and vertigo. Horizontal canal BPPV was then reported by others [40-43] and its particularly intense vertigo confirmed. Early repositioning attempts failed [41]. A 270 degree "barbecue" rotation was trialled [44].

These simple horizontal repositioning techniques remain the usual way of treating the horizontal variant of BPPV (Figure 10). Occasionally the most intense nystagmus is away (apogeotropic) from the undermost ear, implying a particle or particles attached to the cupula, or close to it, on its canal or utricular side $[43,45-47]$. The cupula becomes "heavy" and is ampullofugal when the symptomatic ear is undermost and ampullopetal when it is uppermost. It can be difficult to ascertain which is the symptomatic ear, but it is likely to be the undermost ear which initiates the least nystagmus (Figure 4). Horizontal canal BPPV comprises approximately $15 \%$ in most series. As for posterior canal it can occur de novo, after mild head injury or by "canal conversion" during posterior canal repositioning $[45,46]$. It is likely that patients with horizontal canal BPPV inadvertently treat themselves by rolling over in their sleep, if it is in the desirable direction. It they turn in the "wrong" direction they trigger and awake with vertigo.

Although Brandt et al. [48] in 1994 had alluded to "the rare anterior [superior] canal BPPV, the spontaneous symptoms occur when the affected ear is uppermost", the first detailed description of superior canal BPPV is usually attributed to Herdman and Tusa [49] who documented two patients whose positionally induced nystagmus was accompanied by downbeat and torsional nystagmus likely to be caused by a superior canal receptor and which ceased after repositioning treatment, implying it was rare form of BPPV. Subsequently superior canal BPPV was recognized and reported by others [50-56] in whose series it accounts for approximately $1 \%$ of all BPPV diagnoses. In a review [52] of 50 consecutive patients with positionally induced nystagmus, $75 \%$ had a central cause: multiple system atrophy, cerebellar degeneration, and other miscellaneous causes with immediate onset of downbeat nystagmus on a Dix Hallpike test. In 25\% ("idiopathic") a Dix Hallpike test or a head-hanging test elicited downbeat nystagmus with a short latency. In half the subjects a torsional nystagmus could be seen through Frenzel glasses, but in one it was only discernible by video imaging. Aw et al. [54] studied forty-four patients whose BPPV had not responded to conventional repositioning, using 3-dimensional research coils and a 2-axis wholebody rotator. Seven had downbeat nystagmus with a small torsional component, and all responded to a "head-overheels" forward rotation in the plane of the superior canal. Differences in the ampullary segments of the posterior and superior canals most likely explain why superior canal BPPV downbeat nystagmus can be triggered by a Dix Hallpike test to either side and for its small (or absent) torsional component. In most cases the symptomatic ear is the uppermost ear (Figure 5).

\section{Office Management}

The author uses the simplest repositioning techniques.

2.1. Posterior Canal BPPV. Diagnosis is by the Dix Hallpike test. Older patients with neck, back, and hip problems require special care, and the test can be more simply done over a pillow (Figures 2 and 5). The patient MUST experience vertigo. Occasionally an initial negative test may become strongly positive after the patient does vigorous headshaking. 


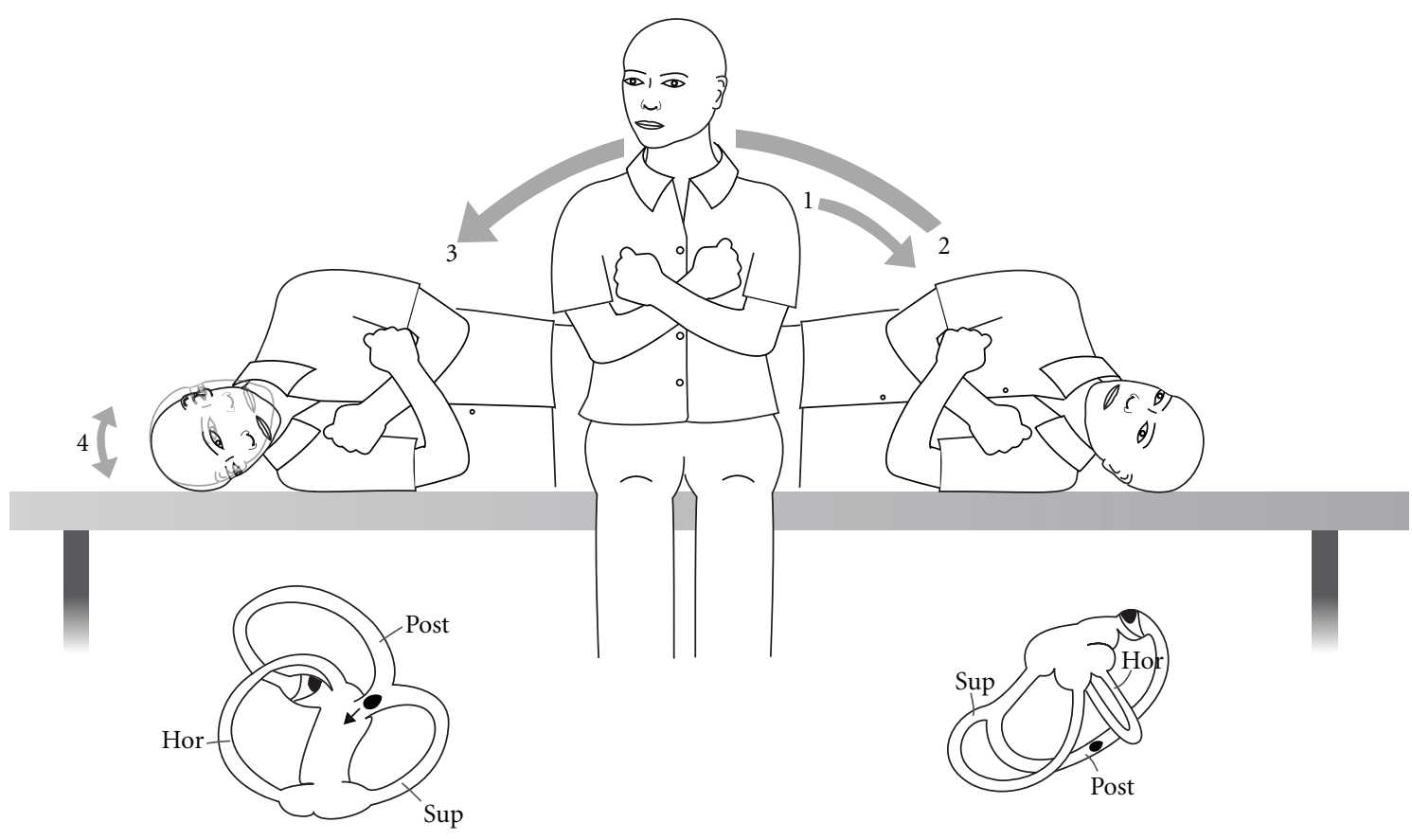

FIgURE 6: Semont maneuver for posterior canal BPPV in a left ear.
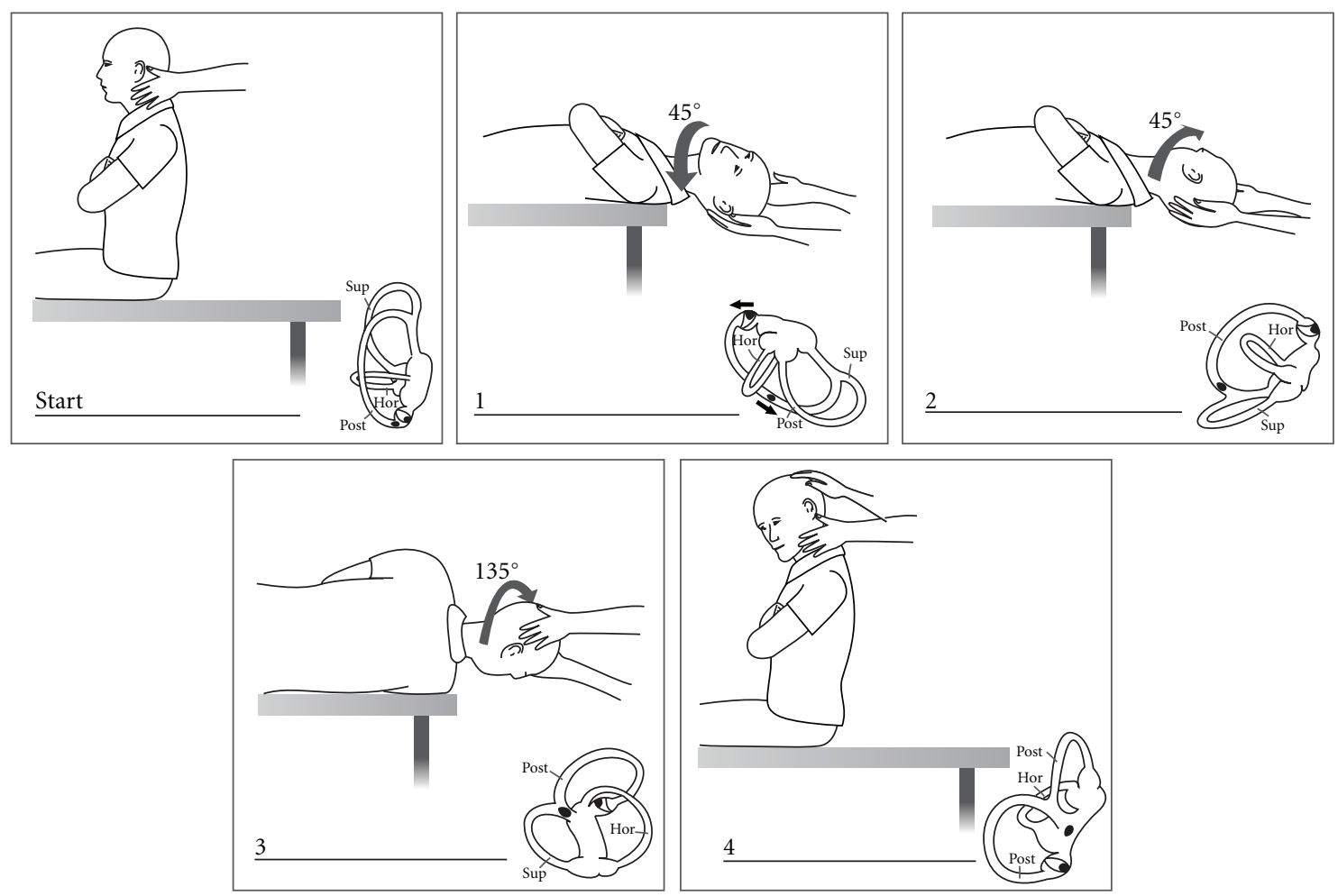

Figure 7: Epley canalith repositioning procedure (CRP).

The most common repositioning treatment is Epley's CRP as modified by Parnes with one-minute pauses between head positions (Figure 7). Following the CRP a repeat Dix Hallpike test is done. If positive, the CRP is repeated with mastoid vibration (Hitachi Magic Wand $250 \mathrm{~Hz}$ massage vibrator). If the test is negative, no further repositioning is done. However it is NOT confirmation of treatment success, and retesting should be done. There is no widely accepted interval. One week is a reasonable goal. Younger, agile patients can be shown how to conduct their own 


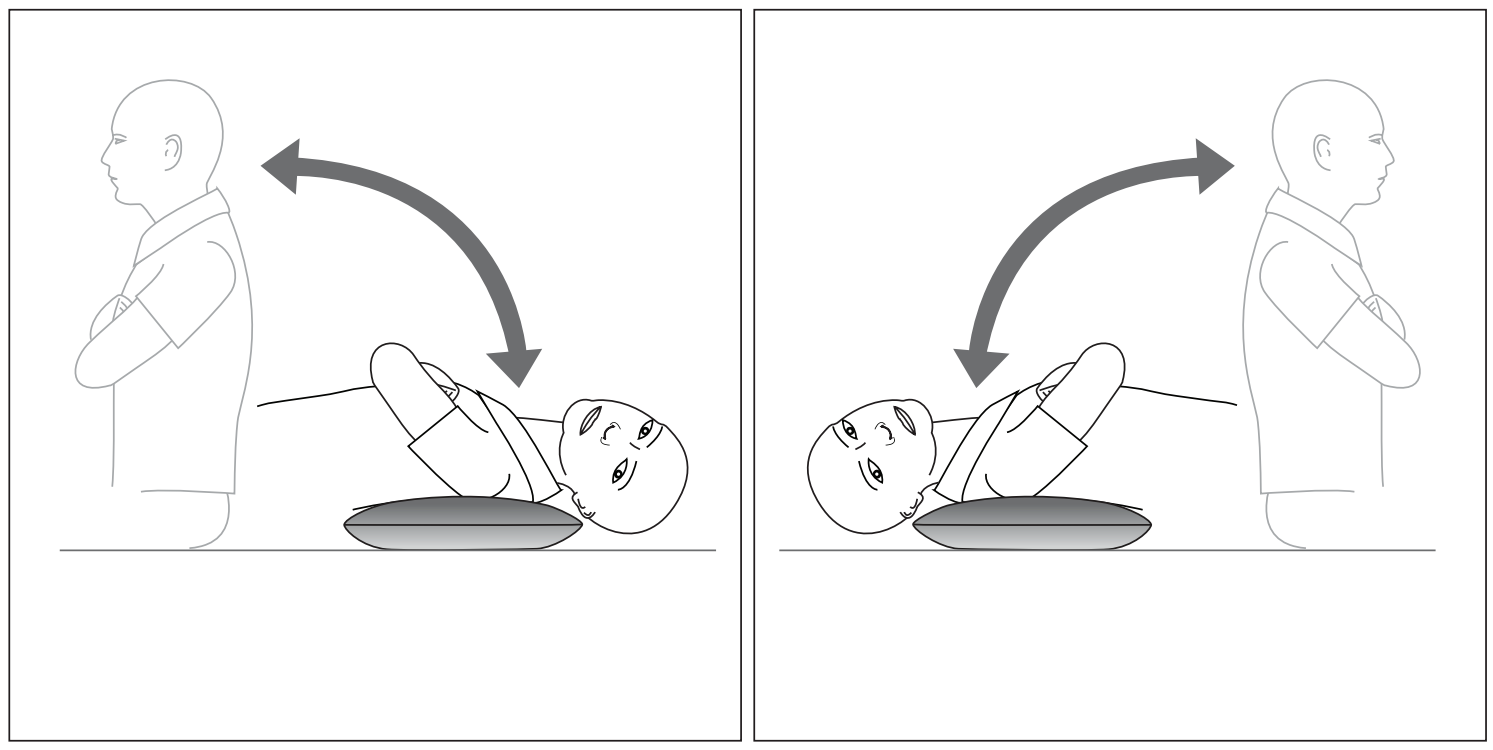

FIGURE 8: Self-testing at home by lying down over a cushion.

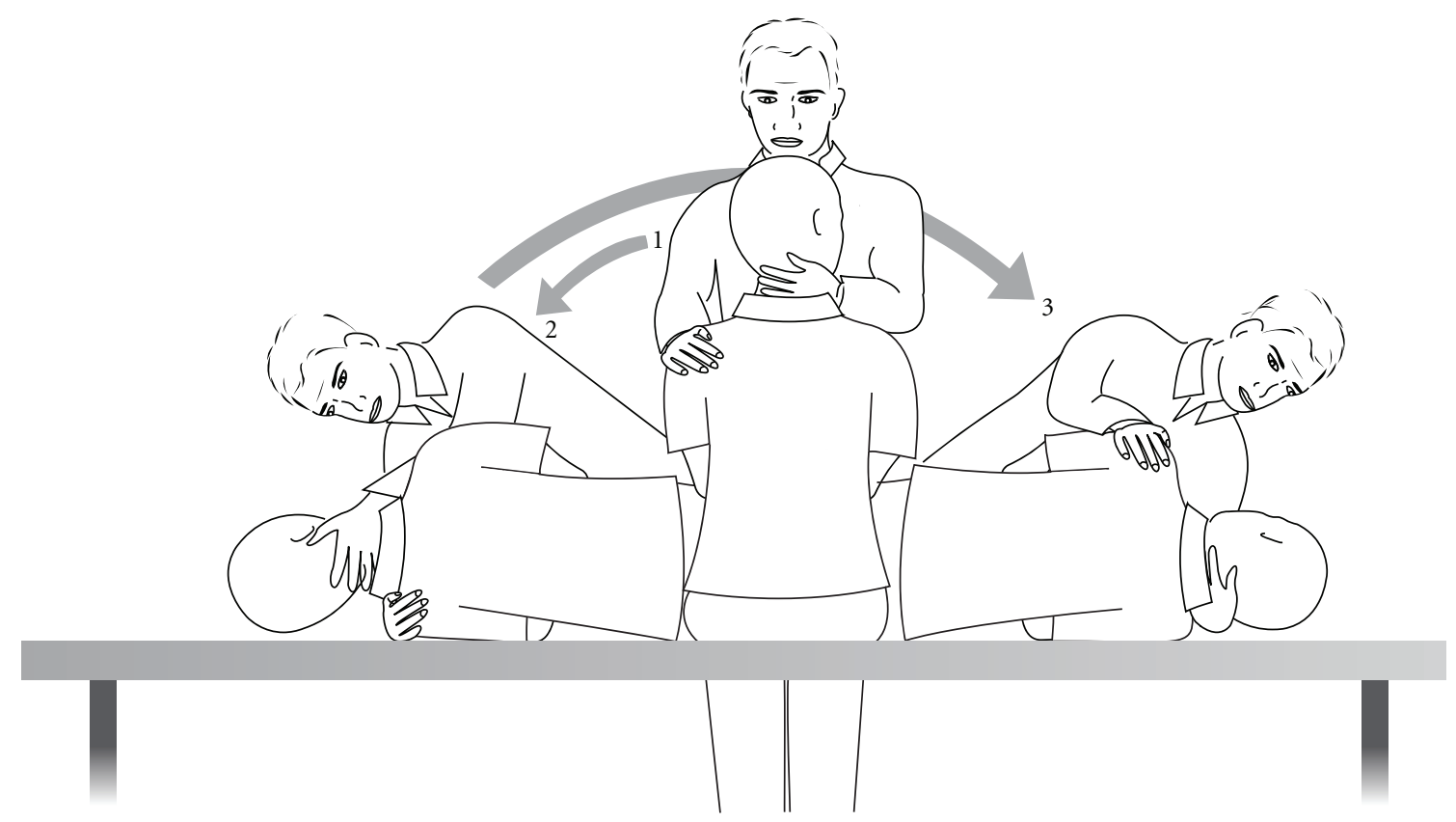

FIGURE 9: Safer technique for performing the Semont maneuver, with the patient moved by a hand under the shoulder and the other hand supporting the neck.

follow-up test at home by lying down over a cushion on the floor (Figure 8). However, older patients, who often report success by avoiding provocative positions, MUST be seen and formally retested.

If at followup the Dix Hallpike test is positive, repeat treatment can be by a further CRP with mastoid vibration or by the Semont maneuver. Descriptions of the Semont maneuver typically show the patient held and moved by two hands around the neck. This is extremely inappropriate for many individuals who are larger, obese, or who have neck problems. A safer technique is for the physician to rapidly move the patient from side to side by a hand under the downmost shoulder (symptomatic ear) and the other supporting the neck (Figure 9).

A Cochrane collaboration review of the Epley CRP and 5 subsequent random controlled trials found a significant success compared with nontreated controls [57, 58]. Comparison of trials is confounded by variation in the number of CRP cycles used per treatment, clinician experience, and the treatment setting. There have been relatively few trials $[59,60]$ 
confirming the efficacy of the Semont maneuver compared with sham treatment. The Semont maneuver is the most logical first treatment for a patient with posterior canal cupulithiasis (immediate nystagmus onset) with attached otoconia more likely to be dislodged by a centrifugal force.

Epley initially recommended that after a CRP the patient should sleep propped up for two nights to prevent repositioned particles from returning [28]. However, numerous studies have not shown any advantage from posttreatment restrictions $[61,62]$. The use of adjunctive mastoid vibration has remained contentious, probably because of the power range of the devices used [63].

The vast majority of BPPV treatment studies have been performed in specialist practice settings. While very few patients can or even wish to administer self-treatment, it is an understandable goal. Self-administered CRP at home after initial office CRP achieved a slightly greater improvement [63]. As an adjunct to self-treatment the newly released "DizzyFix" dynamic visual device (Clearwater Clinical) [64] significantly improved the performance of volunteers learning Parnes' modification of the CRP (Figure 10). It is a useful teaching tool on correct CRP technique for patients and health professionals.

\subsection{Horizontal Canal BPPV. Horizontal canal BPV is most} likely to be discovered as the patient is undergoing a Dix Hallpike provocative test $[46,47]$. Occasionally it suddenly becomes apparent ("canal Conversion") after a CRP, with brisk horizontal-rotatory nystagmus. If there is pillow under the shoulders, it is removed and the patient is moved down the examination couch so that the head is midline and in the horizontal plane. Then the head is gently turned to one side and then the other ("head roll" test). Usually there is a clear, repeatable pattern of brisk nystagmus towards one undermost ear (maximum geotropic) and then weaker nystagmus (apogeotropic) when the opposite ear is down. If a "canal conversion" has occurred, the symptomatic ear is already known. The vertigo tends to be more intense than for posterior canal BPPV, and some patients become nauseated and require an antiemetic. Once the symptomatic ear has been identified, the mechanism and its different repositioning in the horizontal plane ("barbecue" repositioning) are explained to the patient (Figure 11). With the examiner seated at the head of the examination couch the patient is asked to rotate 360 degrees in four stages, a minute apart. At the third position the patient should be resting on the elbows with the neck flexed, so that the horizontal canal is vertical, which is where the particle will exit the canal if it has been successfully moved. The head roll test is repeated and, if negative, treatment ceases.

If on the head roll test the nystagmus is apogeotropic, the likely mechanism is cupulolithiasis in the undermost ear with the least nystagmus. The particle(s) could be on either side of the cupula. On the presumption it is on the canal side the standard direction rotation is carried out. If unsuccessful (likely vestibule side) rotation is done in the opposite direction. Additional headshaking or mastoid vibration can be used. Sometimes apogeotropic nystagmus

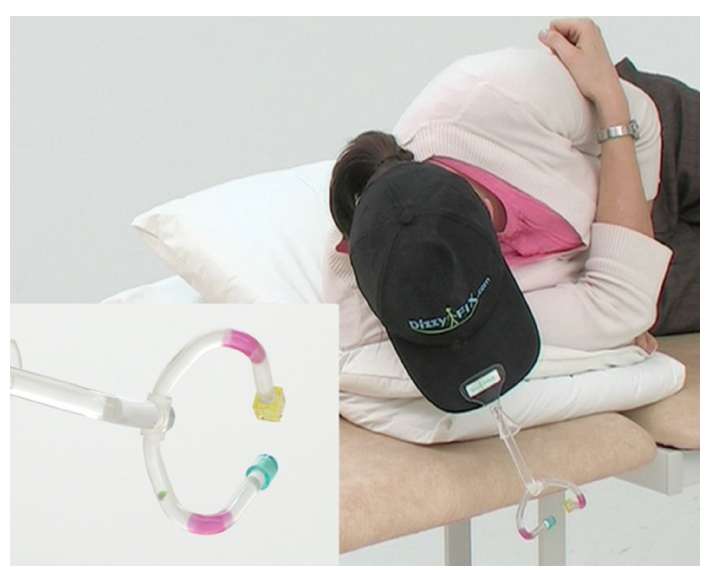

Figure 10: "DizzyFix" dynamic visual device for teaching the modified Epley CRP to patients and health professionals. It is not a model of the semicircular canals but a representation assisting accurate head positioning and appropriate timing for a posterior canal particle to be successfully expelled.

reverses to geotropic, implying that an attached particle(s) has become free. If there is not a clear pattern, or if the patient becomes very nauseated, it is advisable to retest on another day. Central pathology must be kept in mind.

2.3. Superior Canal BPPV. On a Dix Hallpike test if there is downbeat nystagmus superior canal, BPPV is a possibility. If the cause is central, the nystagmus onset is immediate, and the patient does NOT experience vertigo. If it is BPPV, there will be a latency of onset and the patient MUST experience vertigo. Any torsional component may be imperceptible to the naked eye. Repeating the test with the head lower ("headhanging" test) than usual may intensify the response. The particle may be in either ear but most likely in the uppermost ear. On these assumptions there are two simple "office" treatments.

The first is the Epley CRP performed with "head hanging" and commencing with the suspected ear uppermost. The second is the Li maneuver [65] where the patient is moved rapidly from a supine (midline) head-hanging position to a face-down position at the opposite end of the couch (Figure 12).

\subsection{Recurrences, Failed Office Treatment, and Complications.} Reported rates of spontaneous complete resolution of BPPV at a month range from $20 \%$ to $80 \%$. The American Academy of Otolaryngology, Head and Neck Surgery Clinical Practice Guideline, Benign Paroxysmal Positional Vertigo recommends that physician retesting at one month after repositioning treatment should be the standard interval after treatment [58].

Patients treated for BPPV should be told that there is a likelihood of recurrences. Most trials involve a short followup period. In trials with longer followup the recurrence rate at one year is estimated at $15 \%$ [66] and 37\%-50\% at 5 years on the Kaplan-Meier curve [66, 67]. Posttraumatic BPPV 


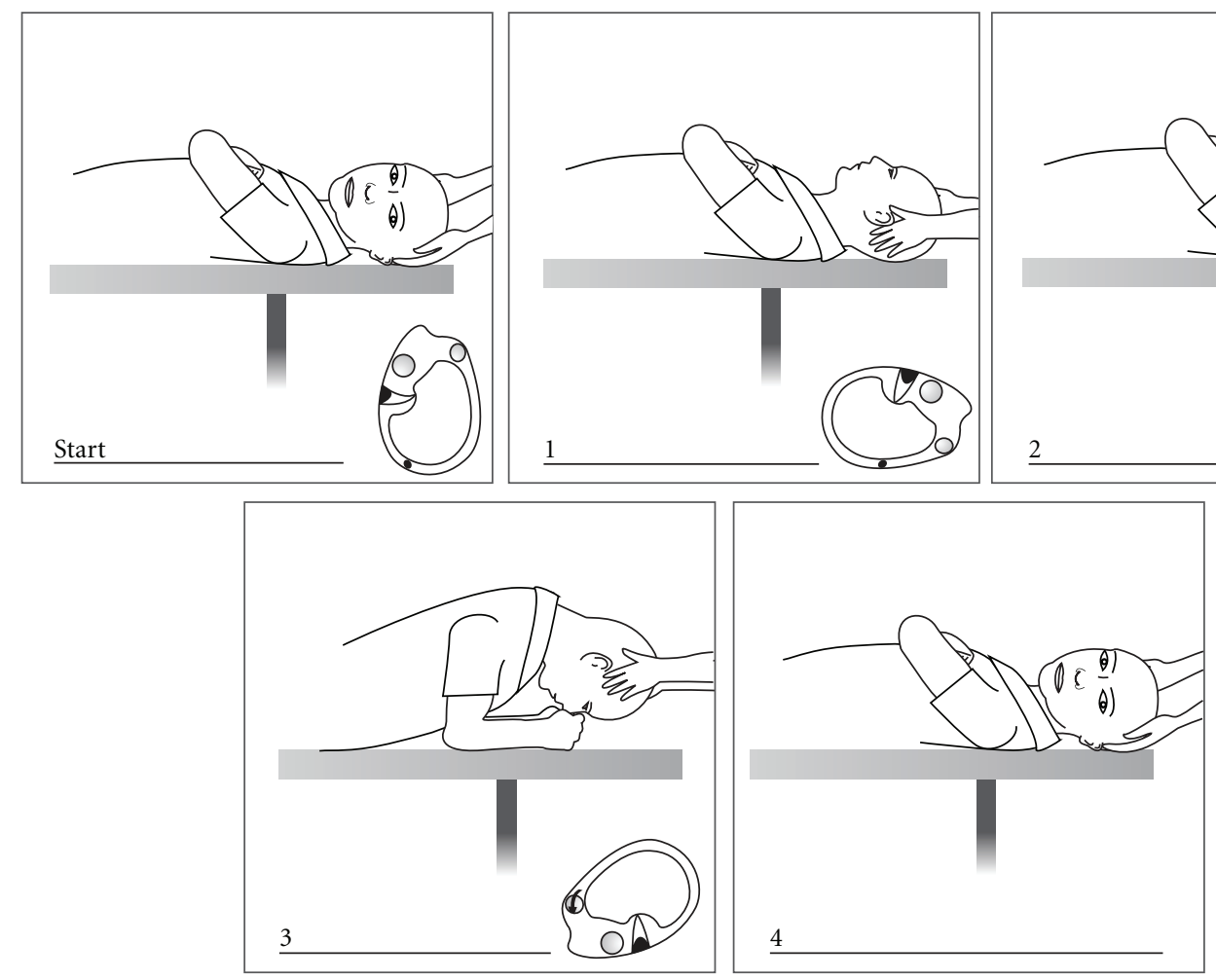

FIGURE 11: "Barbecue" repositioning for horizontal canal BPPV in a left ear.
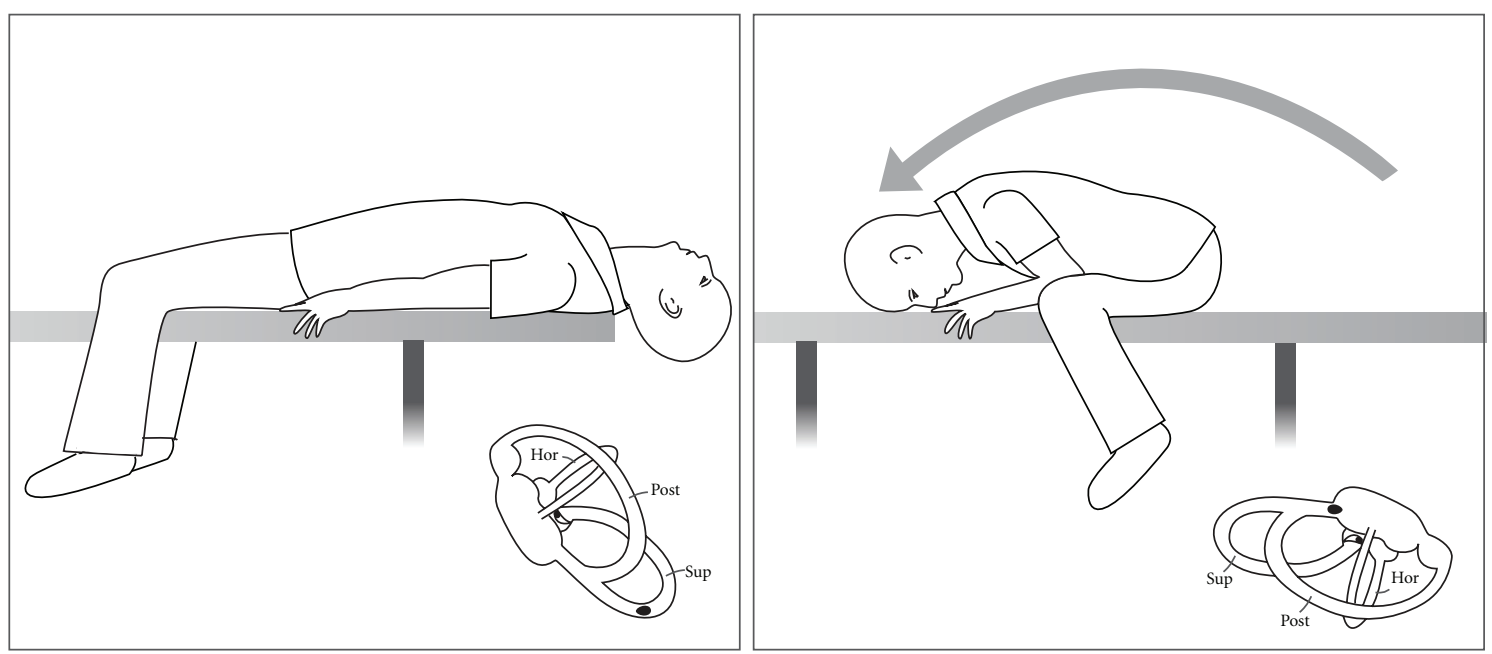

FIGURE 12: The Li manoeuvre for superior canal BPV in either ear (left ear).

may have a higher recurrence rate than spontaneous BPPV [68].

The most common "complication" of BPPV repositioning treatment is canal conversion. Considering the population age in which it is usually performed there is a surprising sparsity of literature on cervical spine and neurological complications [69].

2.5. Central Pathology. Central nervous system disorders can masquerade as BPPV, in particular intracranial tumours
$[52,70,71]$ and migraine. Nystagmus features which strongly suggest a neurological cause are downbeat nystagmus, direction-changing nystagmus without a change in head position, nausea with up or downbeating nystagmus, and preexisting and continuing nystagmus. The cardinal distinguishing feature from BPPV nystagmus is that the patient does NOT experience brief rotational vertigo. Therefore patients with such nystagmus or symptoms of BPPV not showing resolution after repositioning require neurological examination and MRI scanning of the brain and posterior fossa. 
Migraine is now a well-recognised cause of recurrent vertigo [72]. During an episode positional testing can elicit upbeat torsional or horizontal nystagmus similar to BPPV $[73,74]$. Features supporting migraine as a cause are headache, absence of brief acute vertigo induced by the Dix Hallpike test, disappearance of all nystagmus within days, and a recurrent pattern.

\section{Future Directions}

Currently Epley's canalith theory explains most of the features of BPPV: the latency and type of nystagmus, according to the involved canal, and the logic and efficacy of repositioning treatments. However, as for many other inner ear disorders, certain details of its pathophysiology, in particular spontaneous recovery, remain elusive, largely due to the inability to internally image the inner ear in enough detail and the prior reliance on histological techniques. Increased knowledge of human otoconial physiology and pathology will be important.

As episodes of BPPV recover without treatment, it is reasonable to assume that otoconia exit a canal during normal head movement, particularly in horizontal canal and superior canal BPPV. It has been demonstrated that frog otoconia rapidly dissolve in endolymph with physiologic calcium levels, but more slowly if the calcium level is raised [75]. Therefore a major reason for spontaneous recovery is the ability of normal endolymph to dissolve otoconia if they do not return to the utricle. In mammals otoconia are calcite crystals of calcium carbonate. In rats scanning electron microscopy (EM) shows a progressive degeneration of otoconial structure in the oldest rats [76], a phenomenon consistent with the common age range in BPPV. In female rats made artificially oesteopenic/osteoporotic, scanning EM shows ultrastructural changes in otoliths [77] suggesting that there could be relationship between bone biochemistry and recurrent BPPV in older women. Seventy-five percent of thirty-two women aged been 50 and 85 years who had BPPV were shown to have osteopenia or osteoporosis compared with eighty-three healthy controls [78].

Measurement of vestibular-evoked myogenic potentials (VEMPs) is new electro-physiological technqiue for measuring saccule and otolith function. In some patients with vestibular neuritis absence of the cervical VEMPs(c-VEMP) on the side neurolabyrinthitis predicted the nondevelopment of BPPV which only occurred if the cVEMP was present. More recent studies on the "health" of the otolith organs using c-VEMPs $[79,80]$ have shown significantly large number of prolonged responses in patients with BPPV compared with healthy controls, suggesting neuronal degeneration of the saccule. In contrast newer ocular VEMPs (o-VEMP) also measure utricular function and are likely to be more relevant in establishing otolith dysfunction and recovery in BPPV. Distortion of the visual horizontal due to ocular torsion occurs in utricular dysfunction, as in vestibular neuritis. Measurement of the visual horizontal in BPPV patients was abnormal in $42 \%$ before-treatment, 15\% after repositioning and in $8 \%$ two weeks later suggesting initial utricular dysfunction and its possible restoration from the return of otoliths [81]. Encouraging advances in imaging may eventually enable in vivo correlation. Three-dimensional T2-weighted 3-dimensional fast MRI imaging with steadystate acquisition sequences can now show some reliable detail of semicircular structure such as narrowed areas and "filling defects" [82]. In patients with "intractable" BPPV $89 \%$ had abnormal canals compared with healthy controls, but there was no correlation between the affected canal and nystagmus type. Subtle variations in canal diameter, length, and width may correlate with a predisposition to BPPV and to treatment failures.

Finally, the American Academy of Otolaryngology, Head and Neck Surgery Clinical Practice Guideline on BPPV [58] has recommended sixteen aspects meriting further research, including the true prevalence and burden of untreated BPPV in older adults, the natural history of untreated BPPV, agreed endpoints for clinical trials, and importantly the functional impact of BPPV on work safety and the rates of falls it may account for in the elderly.

\section{Conflict of Interests}

The author declares that there is no conflict of interests.

\section{Acknowledgments}

To Debbie Ware at Slipstream Creative (http://www.slipstreamcreative.co.nz/) for illustrations. Video 2 in supplementary material that was available online at doi: 10.1155/2011/835671 (Semont manoeuvre) was filmed by Dr Stuart Mossman, Department of Neurology, Wellington Hospital, Wellington, New Zealand.

\section{References}

[1] K. Kaga, "Personal communication: historical discovery of vestibular peripheral system and new insights on bilateral vestibular neuropathy in patients," Proceedings of the Barany Society XXIII Congress, Paris, France, July 2004.

[2] D. Adler, "Ubeden 'einseitigen Drehschwindel', Dtsch $Z$ Nervenheilkd, pp. 358-375, 1897.

[3] R. Barany, "Diagnose von krankheitserch-eingungen im mereiche de otolithenapparates," Acta Otolaryngol, vol. 2, pp. 434437, 1921.

[4] M. R. Dix and C. S. Hallpike, "The pathology, sympomatology and diagnosis of certain common disorders of the vestibular system," Annals of Otology, Rhinology and Laryngology, vol. 61, pp. 987-1016, 1952.

[5] L. Citron and C. S. Hallpike, "Observations upon the mechanism of positional nystagmus of the so-called "benign paroxysmal type",' Journal of Laryngology \& Otology, vol. 70, pp. 253-259, 1956.

[6] L. Citron and C. S. Hallpike, "A case of positional nystagmus of the so-called benign positional type and the effects of treatment by intracranial division of the VIIIth nerve," Journal of Laryngology \& Otology, vol. 76, pp. 28-33, 1962.

[7] R. J. Ruben, "The development and acceptance of the association of diseases of the ear and disorders of balance. Meniere's disease," in Proceedings Second International Symposium on Meniere's Disease, J. B. Nadol, Ed., pp. 3-11, Kugler, 1989. 
[8] P. Flourens, Recherches sur les condtions fondamentales de l'audition, Memoires de la Société (Royale) des Sciences, December, 1824.

[9] P. Meniere, "Memoire sur des lesions de l'oreille interne dominant lieu a des congestion cerebrale apoplectiforme," Gaz Med Paris, vol. 16, pp. 597-601, 1861.

[10] A. Politzer, History of Otology: From the Earliest Times to the Middle of the Nineteenth Century, vol. 1, Columella Press, 1981, English translation: S. Milstein, C. Portnoff, A. Coleman.

[11] J. R. Ewald, Physiologische Untersuchungen Ueber das Endorgan de Nervus Octavus, Bergmann JF Publishers, Wiesbaden, Germany, 1892.

[12] A. Rejto, "On Ewald's theory relating to the ampullofugal and ampullopetal endolymph currents," The Journal of Laryngology \& Otology, vol. 35, pp. 176-181, 1920.

[13] J. Wersall, "The minute structure of the crista ampullaris in the guinea pig as revealed by the electron microscope," Acta Oto-laryngologica, vol. 44, no. 4, pp. 359-369, 1954.

[14] A. Flock and J. Wersall, "A study of the orientation of the sensory hairs of the receptor cells in the lateral line organ of fish, with special reference to the function of the receptors," The Journal of Cell Biology, vol. 15, pp. 19-27, 1962.

[15] H. H. Lindeman, "Regional differences in structure of the vestibular sensory regions," Journal of Laryngology and Otology, vol. 83, no. 1, pp. 1-17, 1969.

[16] B. Cohen and J. I. Suzuki, "Annals of otology, rhinology and laryngology eye movements from semicircular canal stimulation in the cat," Annals of Otology, Rhinology and Laryngology, vol. 73, pp. 153-169, 1964.

[17] H. F. Schuknecht, "Positional vertigo. Clinical and experimental observations," Transactions of the American Academy of Ophthalmology and Otolaryngol, vol. 66, pp. 319-331, 1962.

[18] H. F. Schuknecht, "Cupulolthiasis," Archives of OtolaryngologyHead \& Neck Surgery, vol. 70, pp. 765-778, 1969.

[19] H. F. Schuknecht and R. R. F. Ruby, "Cupulolithiasis," Advanced Oto-Rhino-Laryng, vol. 20, pp. 434-443, 1962.

[20] R. R. Gacek, "Transection of the posterior ampullary nerve for the relief of benign paroxysmal vertigo," Annals of Otology, Rhinology and Laryngology, vol. 83, pp. 596-605, 1974.

[21] T. Cawthorne, "The physiological basis for head exercises," The Chartered Society of Physiotherapy, vol. 30, pp. 106-107, 1944.

[22] T. Brandt and R. B. Daroff, "Physical therapy for benign paraoxysmal vertigo," Archives of Otolaryngology_Head \& Neck Surgery, vol. 106, pp. 484-485, 1980.

[23] A. Semont and Sterkers, "Reeductaion vestibulare," Cah ORL, vol. 15, pp. 305-309, 1980.

[24] A. Semont, G. Freyss, and E. Vitte, "Curing the BPPV with a liberatory maneuver," Advances in Oto-Rhino-Laryngology, vol. 42, pp. 290-293, 1988.

[25] S. F. Hall, R. R. Ruby, and J. A. McClure, "The mechanics of benign positional vertigo," Journal of Otolaryngology, vol. 8, pp. 151-158, 1979.

[26] J. M. Epley, "Benign paroxysmal vertigo (canalithiasis): diagnosis and non-surgical treatment," in Dizziness and Balance Disorders, I. K. Arenber, Ed., pp. 545-559, Kugler, Amsterdam, The Netherlands, 1993.

[27] L. S. Parnes and J. A. McClure, "Free-floating endolymph particles: a new operative finding during posterior semicircular canal occlusion,” Laryngoscope, vol. 102, no. 9, pp. 988-992, 1992.

[28] J. M. Epley, "The Canalith Repositioning Procedure: for treatment of benign paroxysmal positional vertigo," Oto-
laryngology-Head and Neck Surgery, vol. 107, no. 3, pp. 399404, 1992.

[29] J. Hornibrook, "Treatment for positional vertigo," The New Zealand Medical Journal, vol. 111, no. 1073, pp. 331-332, 1998.

[30] L. S. Parnes and R. Price-Jones, "Particle repositioning maneuver for benign paroxysmal positional vertigo," Annals of Otology, Rhinology and Laryngology, vol. 102, pp. 325-331, 1993.

[31] M. von Brevern, A. Radtke, F. Lezias et al., "Epidemiology of bengin paroxysmal positional vertigo: a population based study," Journal of Neurology Neurosurgery and Psychiatry, vol. 78, pp. 710-715, 2007.

[32] J. S. Oghalai, S. Mandolidis, J. L. Bath, M. G. Stewart, and H. A. Jenkins, "Unrecognised benign positional vertigo in elderly patients," Otolaryngology-Head \& Neck Surgery, vol. 122, pp. 630-634, 2000.

[33] R. A. Davies and L. M. Luxon, "Dizziness following head injury: a neuro-otological study," Journal of Neurology, vol. 242, no. 4, pp. 222-230, 1995.

[34] J. Hornibrook, "Immediate onset of positional vertigo following head injury," The New Zealand Medical Journal, vol. 111, no. 1073, p. 349, 1998.

[35] J. R. Lindsay and W. G. Hemmenway, "Postural vertigo due to unilateral sudden partial loss of vestibular function," Annals of Otology, Rhinology and Laryngology, vol. 65, pp. 695-708, 1956.

[36] K. Gyo, "Benign paroxymsal positional vertigo as a complication of postoperative bedrest," Laryngoscope, vol. 98, no. 3, pp. 332-333, 1988.

[37] J. C. Li, C. J. Li, J. Epley, and L. Weinberg, "Cost-effective management of benign positional vertigo using canalith repositioning," Otolaryngology-Head and Neck Surgery, vol. 122, no. 3, pp. 334-339, 2000.

[38] J. M. Epley, "Positional vertigo related to semicircular canalithiasis," Otolaryngology-Head and Neck Surgery, vol. 112, no. 1, pp. 154-161, 1995.

[39] J. A. McClure, "Horizontal canal BPV," Journal of Otolaryngology, vol. 14, no. 1, pp. 30-35, 1985.

[40] P. Pagnini, D. Nuti, and P. Vannucchi, "Benign paroxysmal vertigo of the horizonal canal," Otorhinolaryngol Rel Spec, vol. 51, no. 3, pp. 161-170, 1989.

[41] R. W. Baloh, K. J. Jacobsen, and V. Honrubia, "Horizontal canal semicircular canal variant of benign positional vertigo," Neurology, vol. 43, pp. 2452-2459, 1993.

[42] G. De La Meilleure, I. Dehaene, M. Depondt, W. Damman, L. Crevits, and G. Vanhooren, "Benign paroxysmal positional vertigo of the horizontal canal," Journal of Neurology Neurosurgery and Psychiatry, vol. 60, no. 1, pp. 68-71, 1996.

[43] D. Nuti, P. Vannucchi, B. Giannini, and P. Pagnini, "Benign paroxysmal positional vertigo of the horizontal canal: a form of canalolithiasis with variable clinical features," Journal of Vestibular Research, vol. 6, pp. 173-184, 1996.

[44] T. Lempert and K. Tiel-Wilck, "A positional maneuver for treatment of horizontal-canal benign positional vertigo," Laryngoscope, vol. 106, no. 4, pp. 476-478, 1996.

[45] T. D. Fife, "Recognition and management of horizontal canal benign positional vertigo," American Journal of Otology, vol. 19, no. 3, pp. 345-351, 1998.

[46] J. Hornibrook, "Horizontal canal benign positional vertigo," Annals of Otology, Rhinology and Laryngology, vol. 113, no. 9, pp. 721-725, 2004. 
[47] J. Hornibrook, "A newly recognised cause of vertigo: horizontal canal variant of benign positional vertigo," The New Zealand Medical Journal, vol. 118, no. 1222, p. U1659, 2005.

[48] T. Brandt, S. Steddin, and R. B. Daroff, "Therapy for benign paroxysmal positioning vertigo, revisited," Neurology, vol. 44, no. 5, pp. 796-800, 1994.

[49] S. J. Herdman and R. J. Tusa, "Complications of the canalith repositioning procedure," Archives of Otolaryngology Head and Neck Surgery, vol. 122, no. 3, pp. 281-286, 1996.

[50] V. Honrubia, R. W. Baloh, M. R. Harris, and K. M. Jacobson, "Paroxysmal positional vertigo syndrome," American Journal of Otology, vol. 20, no. 4, pp. 465-470, 1999.

[51] K. Brandtberg and I. Bergenius, "Treatment of anterior benign positional vertigo by canal plugging: a case report," Acta Otolaryngol, vol. 122, pp. 281-286, 2002.

[52] P. Bertholon, A. M. Bronstein, R. A. Davies, P. Rudge, and K. V. Thilo, "Positional downbeating nystgamus in 50 patients: cerebellar disorders and possible anterior canal canalithiasis," Journal of Neurology Neurosurgery and Psychiatry, vol. 72, pp. 366-372, 2002.

[53] S. Korres, D. G. Balatsouras, A. Kaberos, C. Economou, D. Kandiloros, and E. Ferekidis, "Occurrence of semicircular canal involvement in benign paroxysmal positional vertigo," Otology and Neurotology, vol. 23, no. 6, pp. 926-932, 2002.

[54] S. T. Aw, M. J. Todd, G. E. Aw, L. A. McGarvie, and G. M. Halmagyi, "Benign positional nystagmus: a study of its threedimensional spatio-temporal characteristics," Neurology, vol. 64, no. 11, pp. 1897-1905, 2005.

[55] B. Schratzenstaller, Wagner-Manslau, G. Strasser, and W. Arnold, "Canalithiasis of the superior semicircular canal: an anomaly in benign paroxysmal vertigo," Acta Otolaryngol, vol. 125, pp. 1055-1062, 2005.

[56] J. Hornibrook, "Superior canal benign positional vertigo," New Zealand Medical Journal, vol. 121, no. 1282, pp. 68-71, 2008.

[57] M. Hilton and D. Pinder, "The Epley (canal repositioning) manoeuvre for benign paroxysmal positional vertigo," Cochrane Database of Systematic Reviews, Article ID CD003162, 2004.

[58] N. Bhattacharyya, R. F. Baugh, L. Orvidas et al., "Clinical practice guideline: benign paroxysmal positional vertigo," Otolaryngology-Head and Neck Surgery, vol. 139, no. 5, pp. S47-S81, 2008.

[59] H. S. Cohen and K. T. Kimball, "Effectiveness of treatments for benign paroxysmal positional vertigo of the posterior canal," Otology and Neurotology, vol. 26, no. 5, pp. 1034-1040, 2005.

[60] V. A. Soto, M. J. Bartual, P. S. Santos et al., "Benign paroxysmal vertigo: a comparative prospective study of the efficacy of Brandt and Daroff exercises, Semont and Epley maneuver," Revue de Laryngologie Otologie Rhinologie (Bord), vol. 122, pp. 179-183, 2001.

[61] E. A. S. Massoud and D. J. Ireland, "Post-treatment instructions in the nonsurgical management of benign paroxysmal positional vertigo," Journal of Otolaryngology, vol. 25, no. 2, pp. 121-125, 1996.

[62] R. A. Roberts, R. E. Gans, J. L. DeBoodt, and J. J. Lister, "Treatment of benign paroxysmal positional vertigo: necessity of postmaneuver patient restrictions," Journal of the American Academy of Audiology, vol. 16, no. 6, pp. 357-366, 2005.

[63] E. W. Sargent, A. E. Bankaitis, C. S. Hollenbeak, and J. W. Currens, "Mastoid oscillation in canalith respostioning for paroxysmal postional vertigo," Otology and Neurotology, vol. 22, pp. 205-209, 2001.

[64] M. A. Bromwich and L. S. Parnes, "The Dizzy-Fix: initial results of a new dynamic visual device for the home treatment of benign paroxysmal postional vertigo," Journal of Otolaryngology Head and Neck Surgery, vol. 37, pp. 380-387, 2008.

[65] J. Li and H. Li, "New repositioning techniques for benign paroxysmal positional vertigo: the Li repositioning manoeuvres," Journal of Laryngology and Otology, vol. 124, no. 8, pp. 905-908, 2010.

[66] R. A. Nunez, S. P. Cass, and J. M. Furman, "Short- and long-term outcomes of canalith repositioning for benign paroxysmal posional vertigo," Otolaryngol-Head Neck Surgery, vol. 122, pp. 647-652, 2000.

[67] M. Sakaida, K. Takeuchi, H. Ishinaga, M. Adachi, and Y. Majima, "Long-term outcome of benign paroxysmal positional vertigo," Neurology, vol. 60, no. 9, pp. 1532-1534, 2003.

[68] C. R. Gordon, R. Levite, V. Joffe, and N. Gaoth, "Is posttraumatic benign paroxysmal postional vertigo different from the idiopathic form?" Archives of Neurology, vol. 61, pp. 15901593, 2004.

[69] M. Bergin, P. Bird, and A. Wright, "Internal carotid artery dissection following canalith repositioning procedure," Journal of Laryngology and Otology, vol. 124, no. 5, pp. 575-576, 2010.

[70] E. Sakata, K. Oihtsu, and Y. Itoh, "Positional nystagmus of benign paroxysmal type(BPPN) due to cerebellar vermis lesions," Acta Otolaryngol, supplement 481, pp. 254-257, 1991.

[71] H. M. Dunniway and D. B. Welling, "Intracranial tumours mimicking benign paroxysmal positional vertigo," Otolaryngology-Head \& Neck Surgery, vol. 118, pp. 429-436, 1998.

[72] M. D. Reploeg and J. A. Goebel, "Migraine-associated dizziness: patient characteristics and management options," Otology and Neurotology, vol. 23, no. 3, pp. 364-371, 2002.

[73] M. Von Brevern, A. Radtke, A. H. Clarke, and T. Lempert, "Migrainous vertigo presenting as episodic positional vertigo," Neurology, vol. 62, no. 3, pp. 469-472, 2004.

[74] R. A. Roberts, R. E. Gans, and A. H. Kastner, "Differentiation of migrainous positional vertigo (MPV) from horizontal canal benign paroxysmal positional vertigo (HC-BPPV)," International Journal of Audiology, vol. 45, no. 4, pp. 224-226, 2006.

[75] G. Zucca, S. Valli, P. Valli, P. Perin, and E. Mira, "Why do benign paroxysmal positional vertigo episodes recover spontaneously?" Journal of Vestibular Research: Equilibrium and Orientation, vol. 8, no. 4, pp. 325-329, 1998.

[76] Y. S. Jang, C. H. Hwang, J. Y. Shin, W. Y. Bae, and L. S. Kim, "Age-related changes on the morphology of the otoconia," Laryngoscope, vol. 116, no. 6, pp. 996-1001, 2006.

[77] D. Vibert, A. Sans, M. Kompis et al., "Ultrastructural changes in otoconia of osteoporotic rats," Audiology and Neurotology, vol. 13, no. 5, pp. 293-301, 2008.

[78] D. Vibert, M. Kompis, and R. Hausler, "Benign paroxysmal vertigo in older women may be related to osteoporosis and osteopenia," Annals of Otology, Rhinology and Laryngology, vol. 112, pp. 885-889, 2003.

[79] G. Akkuzu, B. Akkuzu, and L. N. Ozluoglu, "Vestibular evoked myogenic potentials in benign paroxysmal positional vertigo and Meniere's disease," European Archives of OtoRhino-Laryngology, vol. 263, no. 6, pp. 510-517, 2006.

[80] W. S. Yang, S. H. Kim, J. D. Lee, and W. S. Lee, "Clinical significance of vestibular evoked myogenic potentials in 
benign paroxysmal positional vertigo," Otology \& Neurotology, vol. 29, no. 8, pp. 1162-1166, 2008.

[81] S. Iwasaki, Y. Chihara, M. Ushio, A. Ochi, T. Murofishi, and T. Yamasoba, "Effect of the canalith respostioning procedure on subjective visual horizontal in patients with posterior canal benign paraoxysmal postional vertigo," Acta Otolaryngol, vol. 131, pp. 41-45, 2011.

[82] A. Horii, T. Kitihara, and Y. Osaki, "Intractable benign paroxysmal positional vertigo: long-term follow-up and inner ear abnormality detected by three-dimensional magnetic imaging," Otology \& Neurotology, vol. 31, pp. 250-255, 2010. 


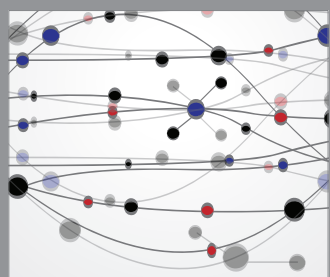

The Scientific World Journal
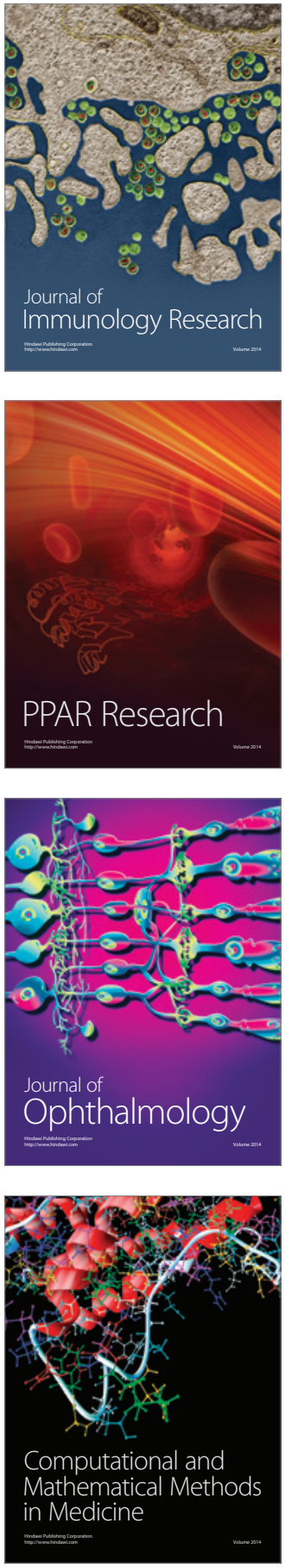

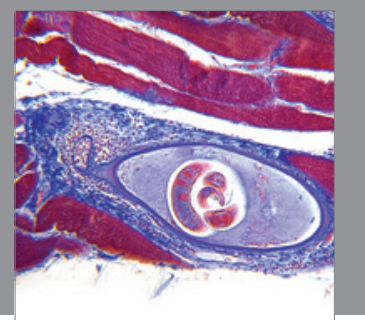

Gastroenterology

Research and Practice
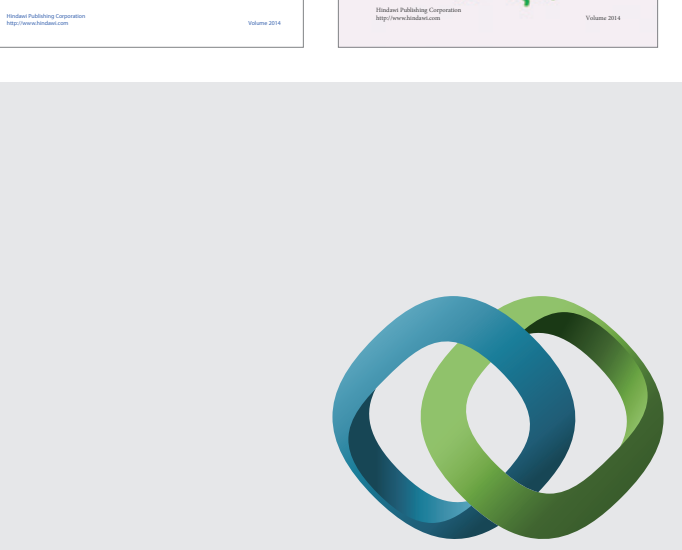

\section{Hindawi}

Submit your manuscripts at

http://www.hindawi.com
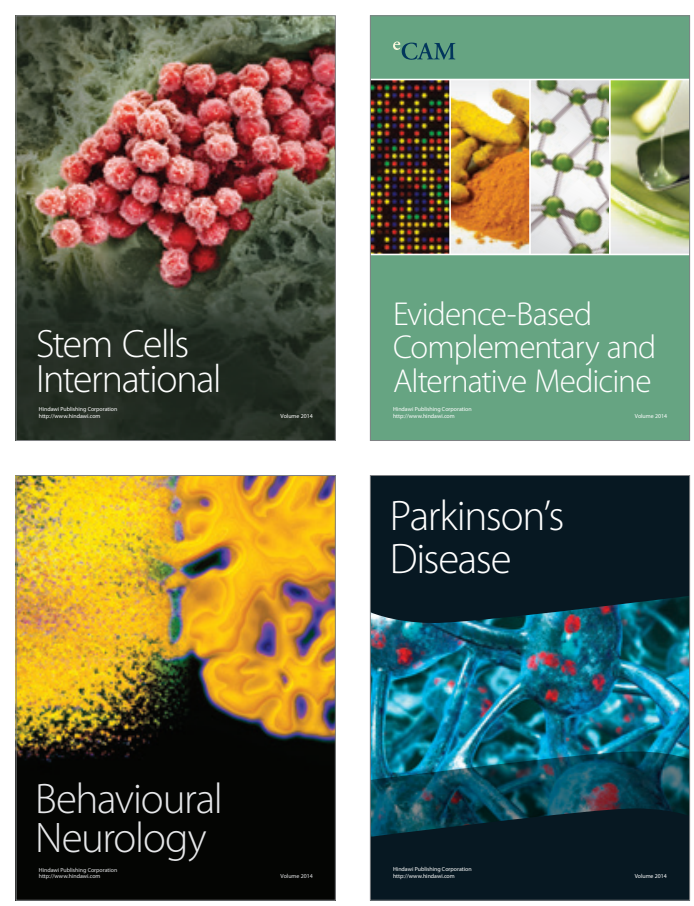

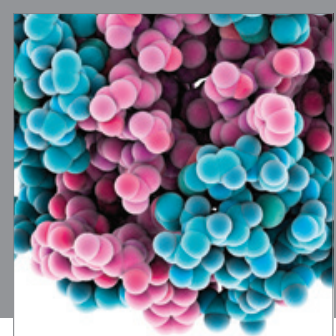

Journal of
Diabetes Research

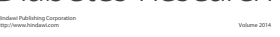

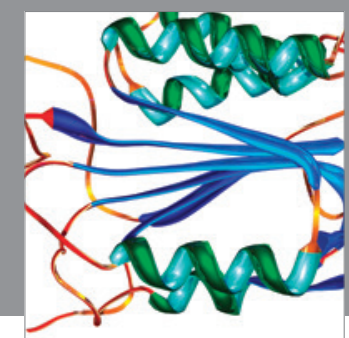

Disease Markers
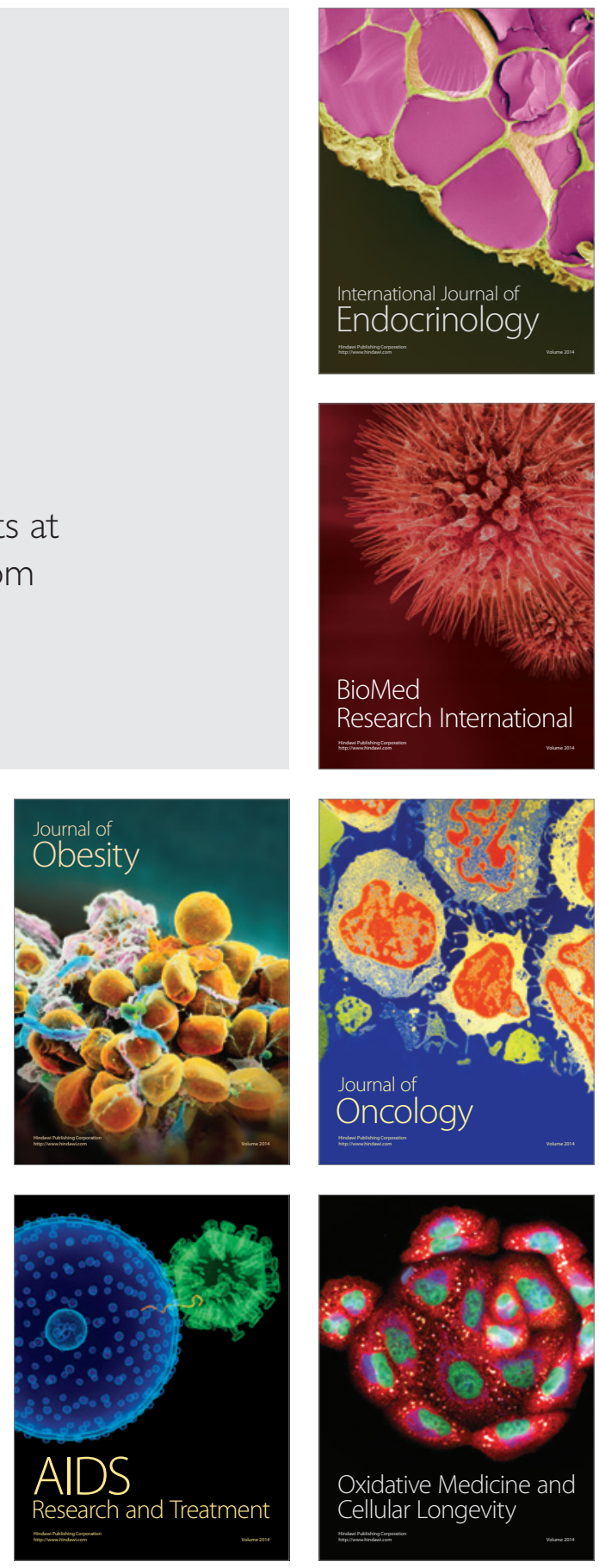